\title{
Radiobiological doses, tumor, and treatment features influence on outcomes after epiescleral brachytherapy. A 20-year retrospective analysis from a single-institution: part II
}

\author{
David Miguel, MPhys',2, Jesús María de Frutos-Baraja, PhD 1,2, Francisco López-Lara, PhD 1,2, María Antonia Saornil, PhD1,2, \\ Ciro Garcia-Álvarez, PhD 1,2, Pilar Alonso, PhD 1,2, Patricia Diezhandino, PhD 1.2 \\ Intraocular Tumor Unit, Hospital Universitario de Valladolid, Valladolid, 2University of Valladolid, Valladolid, Spain
}

\begin{abstract}
Purpose: To assess the influence of the radiobiological doses, tumor, and treatment features on retinopathy, cataracts, retinal detachment, optic neuropathy, vitreous hemorrhage, and neovascular glaucoma at the authors' institution after brachytherapy for posterior uveal melanoma.

Material and methods: Medical records of 243 eyes with uveal melanoma, treated by iodine brachytherapy between 1996 and 2016 at a single center were analyzed. Clinical and radiotherapy data were extracted from a dedicated database. Biologically effective dose (BED) was included in survival analysis performed using Kaplan-Meier and Cox regressions. Relative survival rates were estimated, and univariate/multivariate regression models were constructed for predictive factors of each item. Hazard ratio and confidence interval at $95 \%$ were determined. Variables statistically significant were analyzed and compared by log-rank tests.

Results: The median follow-up was 73.9 months (range, 3-202 months). Cumulative probabilities of survival by Kaplan-Meier analysis at 3 and 5 years, respectively, were: $59 \%$ and $48 \%$ for retinopathy; $71 \%$ and $55 \%$ for cataracts; $63 \%$ and $57 \%$ for retinal detachment; $88 \%$ and $79 \%$ for optic neuropathy; $87 \%$ and $83 \%$ for vitreous hemorrhage; $92 \%$ and $89 \%$ for neovascular glaucoma, respectively. Using multivariate analysis, statistically significant risk factors were: age, tumor apical height, dose to foveola, and location of anterior border for retinopathy; age, dose to lens, type of plaque, and tumor shape, for cataracts; age, tumor apical height, and size of the plaque for retinal detachment; age, plaque shape, longest basal dimension, and BED to optic nerve for optic neuropathy; age, tumor apical height, and tumor shape for vitreous hemorrhage; tumor apical height and BED to foveola for neovascular glaucoma.

Conclusions: Tumor factors in addition to radiation treatment may contribute to secondary effects. Enhanced clinical optimization should evaluate radiobiological doses delivered to the tumor volume and surrounding normal ocular structures.
\end{abstract}

Key words: brachytherapy, radiobiological doses, side effects, uveal melanoma.

\section{Purpose}

Uveal melanoma is a rare malignancy that arises from melanocytes within the uveal tract of the eye. It is the secondmost common form of melanoma and the most common primary intraocular malignancy in adults, affecting from 2 to 8 in Europe [1] and 5.1 individuals per million per year in the World [2]. The primary goals of treating the eye tumor include sparing the eye, preventing metastasis, and preserving vision.

The management of the posterior uveal (ciliary body and choroidal) melanoma depends on tumor size and location, and includes focal transpupillary thermotherapy for small borderline melanoma, resection for anterior tumors, radiotherapy (plaque radiotherapy, external beam radiation therapy, or charged particle irradiation) for small, medium and large melanoma, and enucleation for large melanoma or those encircling the optic disc $[3,4]$.

Plaque brachytherapy is a well-recognized treatment for uveal malignant melanoma [5]. The main purposes of brachytherapy are tumor control, eye preservation, maintenance of vision, and quality of life. The American

Address for correspondence: David Miguel, MD, Intraocular Tumors Unit Valladolid University Hospital, Received: 21.05.2018 University of Valladolid, Spain, C/Avda. Ramón y Cajal s/n, 47003, Valladolid, 47003 Valladolid, Spain, 
Brachytherapy Society (ABS) recommended prescription dose is 85 Gy to the apex of the tumor and encompass small retinal margin of typically $2 \mathrm{~mm}$ [6] using the Collaborative Ocular Melanoma Study (COMS) dosimetry assumptions and plaque construction techniques. It is suggested a dose rate of $0.60-1.05 \mathrm{~Gy} / \mathrm{h}$ delivering the total dose in 3 to 10 consecutive days [7]. Task Group 129 was formed to review the literature, re-examine the current dosimetry calculation formalism, and make recommendations for eye-plaque dosimetry, including evaluation of brachytherapy source dosimetry parameters and heterogeneity correction factors. The American Association of Physicists in Medicine (AAPM) and the ABS recommends that clinical medical physicists should make concurrent estimates of heterogeneity-corrected delivered dose to prepare for brachytherapy [8].

This technique has the advantage of preserving the globe with relatively low radiation exposure to healthy adjacent tissues but may result in significant ocular complications such as retinopathy, maculopathy, cataract, neovascular glaucoma, and nerve atrophy $[9,10,11,12$, $13,14,15]$. The severity mainly depends on the amount of incidental irradiation to the respective tissues and ocular structures radiosensitivity [16].

Radiation induces tissue injury at the cellular level depending of the number of actively dividing cells within that organ or tissue. Although all areas of the eye are susceptible to radiation hurt, different tissues have varying tolerances for radiation exposure. Experiments have shown the effects of ionizing radiation on a cell depending on the total dose and dose exposure rate [17].

Physical dose failed to represent the effect on biological tissues if it is delivered in different fractions of time, or at a different dose rate. The term biologically effective dose (BED), based on linear quadratic cell survival in radiobiology [18] is used in a wide range of clinical situations [19]. Dale, quantitatively evaluated (BED) of non-permanent brachytherapy implants as a function of the implant duration, the radionuclide of treatment, and radiobiological parameters for the tumor and organs at risk (OAR), related with repair rates and radiosensibility [20]. Gagne and colleagues used this model to predict theoretical outcomes [21,22].

Clinical optimization of eye plaque brachytherapy is currently limited to tumor coverage, consensus prescription dosage and dose calculations to ocular structures [23]. Unfortunately, BED is not yet being implemented in the analysis of clinical series of patients treated with brachytherapy plaques.

The aim of this study was to exam patient outcomes: retinopathy, cataracts, retinal detachment, optic neuropathy, vitreous hemorrhage, and neovascular glaucoma (NVG) by survival analysis, and to investigate the influence of radiobiological doses, tumor, and treatment features in patients treated with ${ }^{125} \mathrm{I}$ brachytherapy at our center. We examined the same cohort of previous works, where visual outcomes were studied [24], and rates of local tumor recurrence, enucleation, and survival were considered [25]. In those papers, we also investigated the influence of radiobiological doses, tumor, and treatment features on all those items mentioned.

\section{Material and methods}

\section{Patients diagnosis treatment, workflow, and treatment features}

The patient diagnosis, data collection, patient follow-up, clinical target volume definition, treatment protocol dosimetry, inclusion and exclusion criteria, BED calculation, collected descriptive data on tumor, treatment and patient parameters, patient demographics have been described previously [25].

\section{Event definition}

Radiation retinopathy was defined as any retinal capillary bed changes (retinal hard exudates, hemorrhages, microaneurysms, cotton-wool spots, and telangiectasias), retinal exudation, edema, vascular sheathing, nerve fibre layer infarctions, or neovascularization in peripheral retina. It is considered as maculopathy, when any of the above changes in foveal area is affecting central vision $[26,27,28,29]$. We do not differentiate into maculopathy and retinopathy in this study. Cataract was defined as any loss of transparency of the lens in the eye as a result of tissue breakdown and protein clumping [30]. Radiation optic neuropathy was defined as any hemorrhage, peripapillary exudation, optic disc swelling, or atrophy [28]. Vitreous hemorrhage was defined as any amount of vitreous blood [31]. NVG was defined as the presence of iris and/ or angle new vessels and elevated intraocular pressure [32]. Scleral necrosis was defined as any thinning of the sclera permitting visualization of uveal tissue [33]. Pain was determined as persistent discomfort with a duration of more than three months. Diplopy was defined as the disorder of vision, in which two images of a single object are seen with a duration of more than three months. Ptosis was defined as a permanent descent of the upper eyelid scleral. Necrosis was defined as clinically evident necrosis after radiotherapy. Finally, epiretinal membrane was determined as a semitranslucent, fibrocellular membrane on the inner surface of the retina. Late side effects were recorded until death or lost to follow-up.

\section{Statistics}

Prognostic factors for each item were evaluated by Kaplan-Meier and univariate/multivariate proportional hazards analysis, as a function of dose to different tissues treatment and characteristics features of the tumor.

For each item, survival times were estimated with 95\% confidence intervals (CI) by Kaplan-Meier analysis survival [34] and reported at 3, 5, 10 and 15 years follow-up. Cox regression analysis was used to evaluate the association of the prognostic factors and the estimation of relative risks in each event verifying the proportional hazards hypothesis with a test in each case. To assess toxicity, a descriptive analysis was performed and logistic regression analysis was performed to check for association between factors [35]. Hazard ratio (HR) and 95\% CI for variables that showed a high degree of correlation set as $p<0.1$ were determined and included in a final multivariate model fitted variables, identified as significant 
predictors in the backward stepwise model [36]. For simplicity, the univariate study tables were not presented.

Finally, Kaplan-Meier analysis and estimation of differences using the Log-rank test [34] was performed for those quantitative and qualitative variables, whose multivariate study of proportional hazards presented statistical significance. For quantitative variables, we shared the sample into its median value in order to ensure the same number of data in both branches. For qualitative variables, split was already made, and we analyzed each category.

Applying the most accepted scales of causality from the Council for International Organizations of Medical Sciences (CIOMS), we separated the pathologies between very frequent and frequent according to whether at the end of the study they affected more than $10 \%$ of the patients, or between $10 \%$ and $1 \%$, respectively $[37,38]$. Side effects below $1 \%$ were considered infrequent and were not studied. The justification for this procedure is that survival analyzes, when there are very few affirmative events (below $10 \%$ of the cohort), do not allow a rigorous analysis using the Log-rank estimators [39].

All variables were analyzed as discrete variables except age, apical height, longest basal dimension, activity and treatment time, plaque size, radiation doses and BED, which were analyzed as continuous variables. Data were summarized as mean, standard deviation (SD), median, and interquartile range (IQR) for continuous variables and proportions for categorical variables. Outliers data were removed.

To allow for multiple comparisons, the level of statistical significance was set at $p<0.05$. All analyses were conducted using SPSS version 24.0 (IBM, Somers, NY, USA) and XLSTAT version 2016.02.28451 (Addinsoft, NY, NY, USA).

\section{Results}

\section{Patients}

From 1996 through June 2016, 714 patients with iris, choroidal, or ciliary body melanomas were diagnosed and 303 were treated by brachytherapy. Twenty patients $(6.6 \%)$ were not eligible for the study because a ruthenium plaque treatment was performed and $40(13.2 \%)$ patients were treated with transpupillary thermotherapy or loss follow-up. Ultimately, 243 patients met the inclusion criteria. The median follow-up was 74.5 months (range, 3-202 months). Doses, tumor, and treatment features can be found in Tables 1 and 2 from a previous paper with the same patient cohort [25].

The studied items ordered by number of occurrences have been: radiation retinopathy, cataracts, retinal detachment, optic neuropathy, and vitreous hemorrhage. Other side effects not included in statistical analysis were: pain $(6.1 \%)$, diplopy $(5.7 \%)$, ptosis $(2.8 \%)$, scleral necrosis $(2.4 \%)$, and epiretinal membrane $(0.8 \%)$. In all of them, the proportion of affirmative events in our patient cohort did not exceed $10 \%$.

\section{Radiation retinopathy}

From our cohort of 243 patients, retinopathy was observed in 115 (47\%) patients. Actuarial KaplanMeier curves and confidence intervals are described in Figure 1. The 3-, 5-, 10-, and 15-year probability for retinopathy-free recurrence were: 59\% (95\% CI: 54-64\%), $48 \%$ (95\% CI: $41-55 \%$ ), 36\% (95\% CI: $28-45 \%$ ), and $25 \%$ (95\% CI: $11-39 \%$ ), respectively (Table 1). The mean time to local failure was 88.7 months (95\% CI: 76-102) and the median time was 51 months (95\% CI: 36-67).

Multivariate logistic regression analysis, including age, showed that age (HR: 0.978; 95\% CI: 0.965-0.992; $p=0.002$ ),

Table 1. Mortality table for retinopathy, cataracts, retinal detachment, neuropathy, vitreous hemorrhage, and neovascular glaucoma. T(yr) is the time of follow-up in years, $n$ is the number of patients at risk, and SP is the survival probability (\%)

\begin{tabular}{|c|c|c|c|c|c|c|c|c|c|c|c|c|c|c|c|c|c|c|}
\hline Event & $\mathrm{T}(\mathrm{yr})$ & 0 & 1 & 2 & 3 & 4 & 5 & 6 & 7 & 8 & 9 & 10 & 11 & 12 & 13 & 14 & 15 & 16 \\
\hline \multirow[t]{2}{*}{ Retinopathy } & $n$ & 243 & 210 & 135 & 97 & 75 & 62 & 52 & 40 & 31 & 25 & 18 & 14 & 7 & 5 & 3 & 2 & 2 \\
\hline & SP & 100 & 92 & 71 & 59 & 52 & 48 & 43 & 41 & 39 & 39 & 36 & 36 & 32 & 32 & 25 & 25 & 25 \\
\hline \multirow[t]{2}{*}{ Cataracts } & $n$ & 243 & 198 & 156 & 118 & 95 & 75 & 56 & 44 & 35 & 27 & 21 & 13 & 9 & 7 & 3 & 3 & 3 \\
\hline & SP & 100 & 87 & 81 & 71 & 61 & 55 & 49 & 45 & 45 & 45 & 45 & 38 & 38 & 38 & 38 & 38 & 38 \\
\hline \multirow{2}{*}{$\begin{array}{l}\text { Retinal } \\
\text { detachment }\end{array}$} & $n$ & 243 & 162 & 124 & 102 & 90 & 72 & 64 & 53 & 41 & 35 & 28 & 21 & 18 & 13 & 9 & 7 & 4 \\
\hline & SP & 100 & 69 & 63 & 63 & 61 & 57 & 57 & 55 & 55 & 55 & 55 & 52 & 52 & 49 & 49 & 49 & 49 \\
\hline \multirow[t]{2}{*}{ Neuropathy } & $n$ & 243 & 225 & 178 & 142 & 119 & 101 & 84 & 66 & 53 & 43 & 33 & 24 & 15 & 13 & 10 & 9 & 5 \\
\hline & SP & 100 & 99 & 92 & 88 & 82 & 79 & 76 & 70 & 69 & 68 & 66 & 64 & 61 & 61 & 61 & 61 & 53 \\
\hline \multirow{2}{*}{$\begin{array}{l}\text { Vitreous } \\
\text { hemorrhage }\end{array}$} & $n$ & 243 & 211 & 177 & 146 & 130 & 109 & 92 & 77 & 61 & 50 & 40 & 31 & 23 & 16 & 9 & 7 & 5 \\
\hline & SP & 100 & 92 & 91 & 87 & 86 & 83 & 81 & 78 & 77 & 77 & 75 & 73 & 73 & 73 & 73 & 73 & 73 \\
\hline \multirow{2}{*}{$\begin{array}{l}\text { Neovascular } \\
\text { glaucoma }\end{array}$} & $n$ & 243 & 225 & 188 & 154 & 137 & 117 & 101 & 86 & 67 & 55 & 41 & 30 & 22 & 16 & 10 & 8 & 4 \\
\hline & SP & 100 & 98 & 97 & 92 & 90 & 89 & 88 & 87 & 85 & 85 & 81 & 79 & 76 & 76 & 76 & 76 & 76 \\
\hline
\end{tabular}


Table 2. Multivariable Cox regression analysis of retinopathy, cataracts, retinal detachment, neuropathy, vitreous hemorrhage, and neovascular glaucoma

\begin{tabular}{|c|c|c|c|c|}
\hline \multirow[t]{2}{*}{ Factor } & \multirow[t]{2}{*}{$p$} & \multirow[t]{2}{*}{$\mathrm{HR}$} & \multicolumn{2}{|c|}{$95 \% \mathrm{Cl}$ for $\mathrm{HR}$} \\
\hline & & & Lower & Top \\
\hline \multicolumn{5}{|l|}{ Retinopathy } \\
\hline Age (years) & 0.002 & 0.978 & 0.965 & 0.992 \\
\hline Tumor apical height (mm) & 0.003 & 1.138 & 1.046 & 1.238 \\
\hline Dose to foveola (Gy) & 0.000 & 1.005 & 1.002 & 1.008 \\
\hline \multicolumn{5}{|l|}{ Location of anterior tumor border } \\
\hline Ciliary body & 0.049 & & & \\
\hline Equator to ora serrata & 0.016 & 3.150 & 1.241 & 7.993 \\
\hline Posterior to equator & 0.018 & 3.186 & 1.221 & 8.315 \\
\hline \multicolumn{5}{|l|}{ Cataracts } \\
\hline Age (years) & 0.049 & 1.015 & 1.000 & 1.030 \\
\hline Dose to lens (Gy) & 0.000 & 1.154 & 1.078 & 1.236 \\
\hline \multicolumn{5}{|l|}{ Tumor shape } \\
\hline Mushroom & 0.029 & & & \\
\hline Diffuse & 0.008 & 7.790 & 1.720 & 35.279 \\
\hline Nodular & 0.474 & 1.178 & 0.753 & 1.842 \\
\hline Type of plaque (ROPES vs. COMS) & 0.001 & 2.065 & 1.345 & 3.170 \\
\hline \multicolumn{5}{|l|}{ Retinal detachment } \\
\hline Tumor apical height (mm) & 0.000 & 1.261 & 1.155 & 1.377 \\
\hline Size of the plaque (mm) & 0.005 & 1.174 & 1.048 & 1.315 \\
\hline \multicolumn{5}{|l|}{ Neuropathy } \\
\hline Age (years) & 0.015 & 0.975 & 0.956 & 0.995 \\
\hline Shape plaque (notched vs. not notched) & 0.049 & 2.025 & 1.002 & 4.094 \\
\hline Longest basal dimension (mm) & 0.003 & 1.174 & 1.057 & 1.304 \\
\hline BED to ON & 0.016 & 1.002 & 1.000 & 1.003 \\
\hline \multicolumn{5}{|l|}{ Vitreous hemorrhage } \\
\hline Age (years) & 0.026 & 1.030 & 1.004 & 1.057 \\
\hline Tumor apical height (mm) & 0.049 & 1.157 & 0.999 & 1.341 \\
\hline \multicolumn{5}{|l|}{ Tumor shape } \\
\hline Mushroom & 0.048 & & & \\
\hline Diffuse & 0.978 & 0.000 & 0.000 & \\
\hline Nodular & 0.017 & 0.422 & 0.208 & 0.855 \\
\hline \multicolumn{5}{|l|}{ Neovascular glaucoma } \\
\hline Tumor apical height (mm) & 0.000 & 1.666 & 1.386 & 2.003 \\
\hline BED to foveola (Gy) & 0.003 & 1.001 & 1.001 & 1.002 \\
\hline
\end{tabular}

$B E D$ - biologically effective dose 
tumor apical height (HR: 1.005; 95\% CI: 1.002-1.008; $p<0.001$ ), dose to foveola (HR: 1.005 ; 95\% CI: $1.002-$ $1.008 ; p=0.000)$, location in equator-ora vs. ciliary body (HR: 3.150; 95\% CI: 1.241-7.993; $p=0.016$ ), and location in post-ecuad vs. ciliary body (HR: 3.186; 95\% CI: 1.2218.315; $p=0.018$ ) were significant (Table 2).

Figure 2 shows the study of survival curves for the relevant variables of the multivariate study. All four variables (age, tumor apical, height, dose to foveola, and location of

CSF: Retinopathy

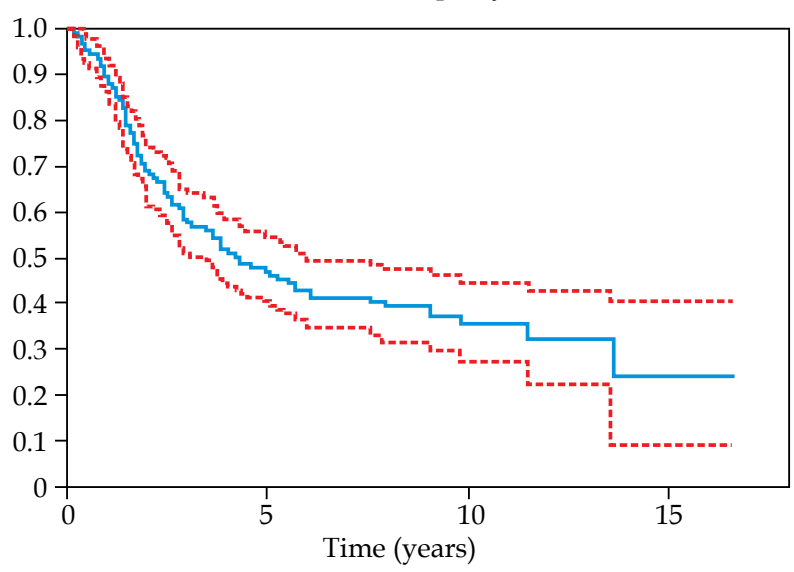

CSF: Retinal detachment

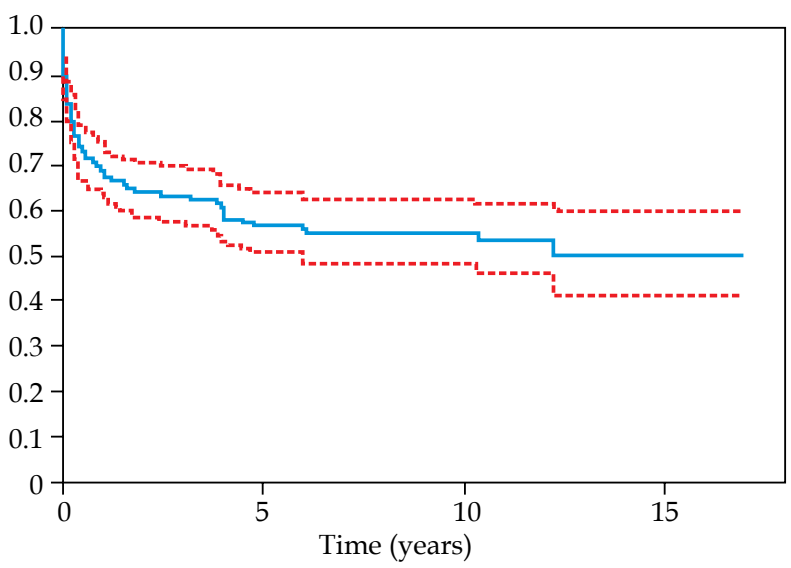

CSF: Vitreous hemorrhage

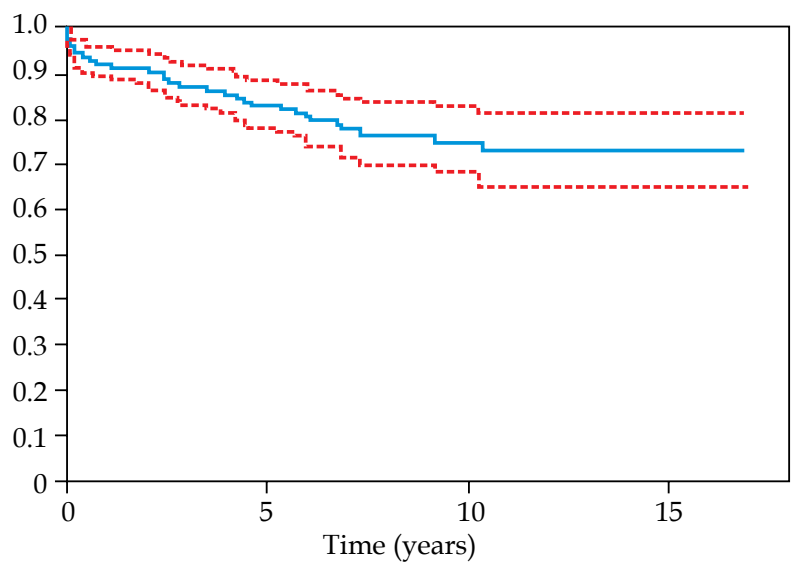

anterior tumor border) analyzed by the log-rank test reported $p$ values less than 0.05 , so the survival curves differ significantly.

\section{Cataracts}

From our cohort of 243 patients, cataracts were observed in 101 (42\%) patients. Actuarial Kaplan-Meier curves and confidence intervals are described in Figure 1. The 3-, 5-, 10-, and 15-year probability for retinopathy-free

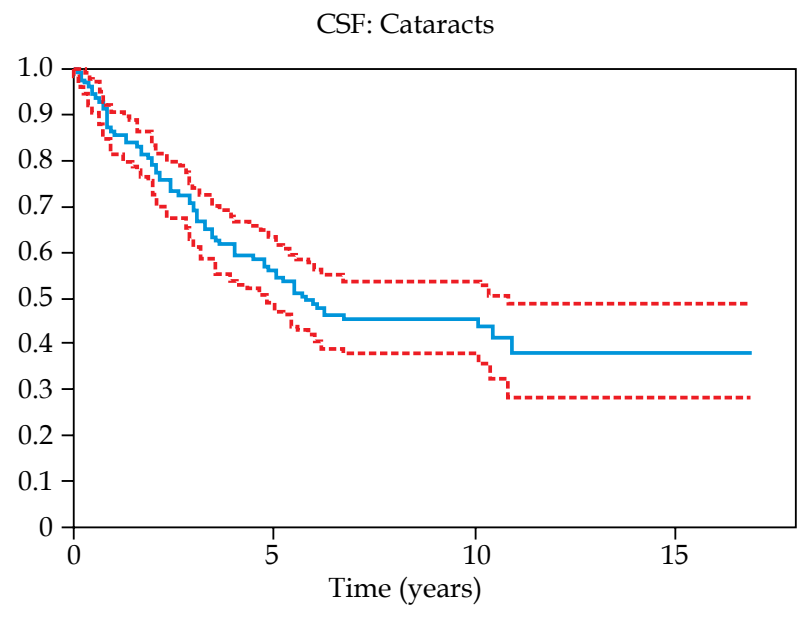

CSF: Neuropathy

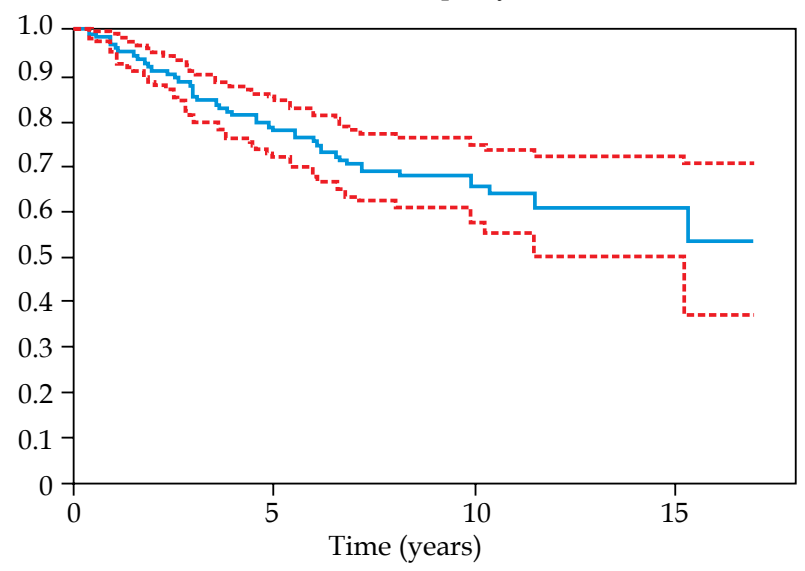

CSF: Neovascular glaucoma

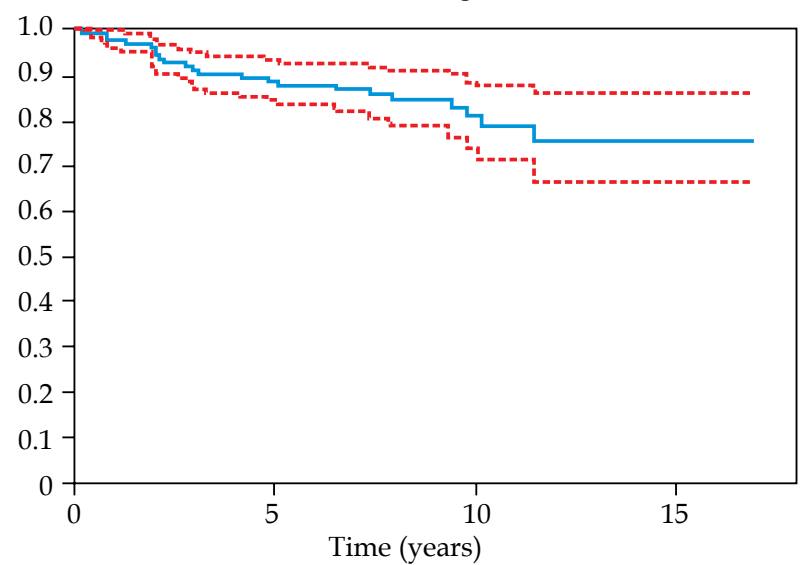

Fig. 1. Kaplan-Meier cumulative survival functions for retinopathy, cataracts, retinal detachment, neuropathy, vitreous hemorrhage and neovascular glaucoma-free survival (blue solid line) with confidence interval (red dashed line) 
CSF: Age, $p<0.001$

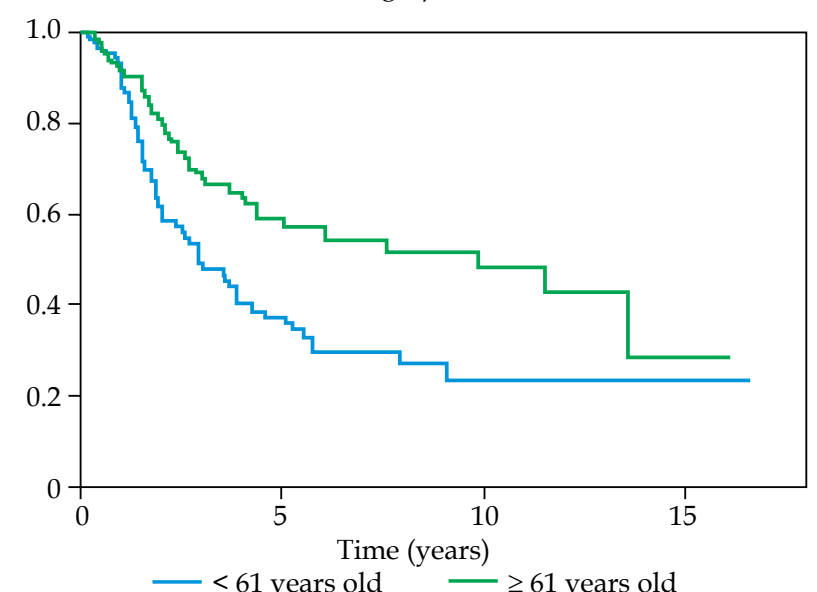

CSF: Anterior tumor border, $p=0.024$

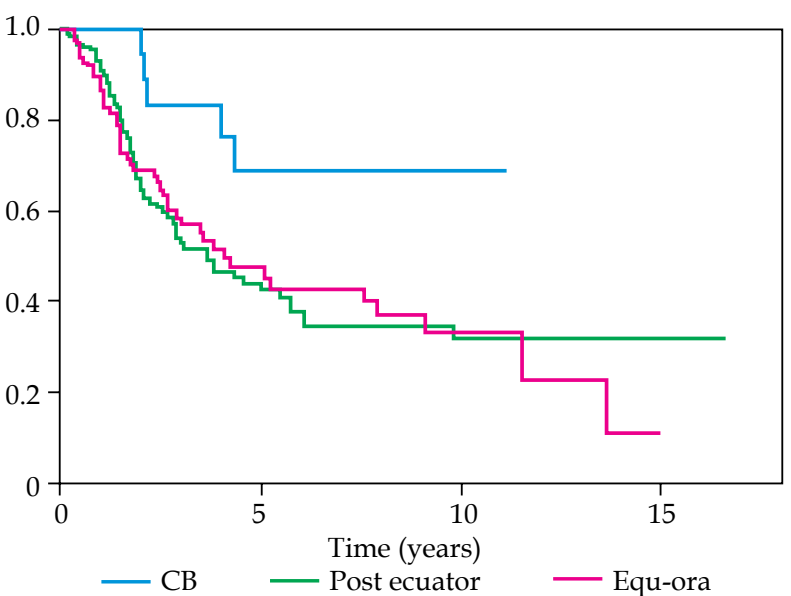

CSF: Tumor apical heigh, $p=0.003$

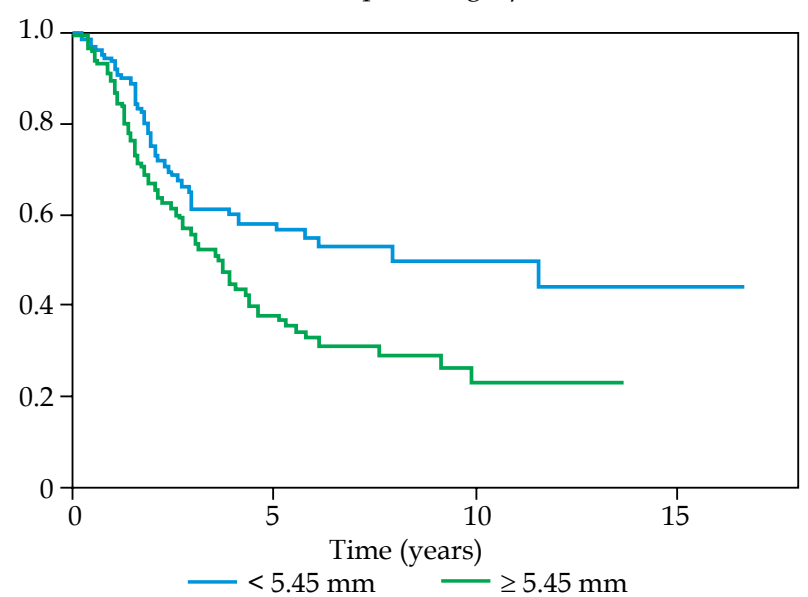

CSF: Dose to foveola, $p<0.001$

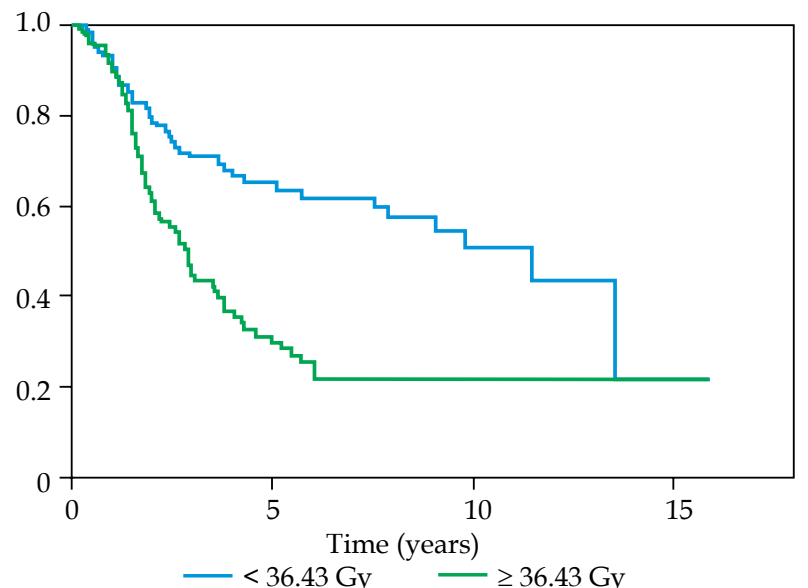

Fig. 2. Kaplan-Meier cumulative survival functions for the retinopathy. For quantitative variables, we shared the sample into its median value in order to ensure the same number of data in both branches. For the qualitative variables, split was already made.

The curves in each of the graphs are not overlapping and there is statistically significant difference by Log-rank test $(p<0.05)$

recurrence were: $71 \%$ (95\% CI: $66-76 \%), 55 \%(95 \% \mathrm{CI}$ : 49-61\%), 45\% (95\% CI: 37-53\%), and 38\% (95\% CI: 28-48\%), respectively (Table 1). The mean time to local failure was 104 months (95\% CI: 90-118), and the median time was 68 months (95\% CI: 29-107).

Multivariate logistic regression analysis including age revealed that age (HR: 1.015; 95\% CI: 1.000-1.030; $p=0.049$ ), dose to lens (HR: 1.154; 95\% CI: 1.078-1.236; $p=0.000$ ), type of plaque, ROPES vs. COMS (HR: 2.065; 95\% CI: 1.345-3.170; $p<0.001)$, and mushroom tumor shape vs. nodular (HR: 7.790; 95\% CI: 1.720-35.279; $p=0.008$ ) were significant (Table 2).

Figure 3 shows the study of survival curves for the relevant variables of the multivariate study. Three variables (dose to lens, type of plaque, and tumor shape) analyzed by the Log-rank test reported $p$ values less than 0.05 , so the survival curves differ significantly. Log-rank test for age was not statistically significant.

\section{Retinal detachment}

From our cohort of 243 patients, retinal detachment was observed in 100 (42\%) patients. Actuarial Kaplan-Meier curves and confidence intervals are described in Figure 1. The 3-, 5-, 10-, and 15-year probability for retinopathy-free recurrence were: $63 \%$ (95\% CI: 57-69\%), 57\% (95\% CI: 50-64\%), 55\% (95\% CI: 48-62\%), and 49\% (95\% CI: 39-59\%), respectively (Table 1). The mean time to local failure was 125 months (95\% CI: 110-140).

Multivariate logistic regression analysis including age revealed that tumor apical height (HR: 1.261; 95\% CI: 1.155-1.377; $p<0.001$ ) and size of the plaque (HR: 1.174; 95\% CI: $1.048-1.315 ; p=0.005$ ) were significant (Table 2).

Figure 4 shows the study of survival curves for the relevant variables of the multivariate study. All two variables (tumor apical height and size of the plaque) analyzed by the Log-rank test reported $p$ values less than 0.05 , so the survival curves differ significantly.

\section{Radiation optic neuropathy}

From our cohort of 243 patients, radiation optic neuropathy was observed in $53(22 \%)$ patients. Actuarial Kaplan-Meier curves and confidence intervals are described in Figure 1. The 3-, 5-, 10-, and 15-year probability for retinopathy-free recurrence were: 88\% (95\% CI: 83-93\%), 
CSF: Age, $p=0.192$

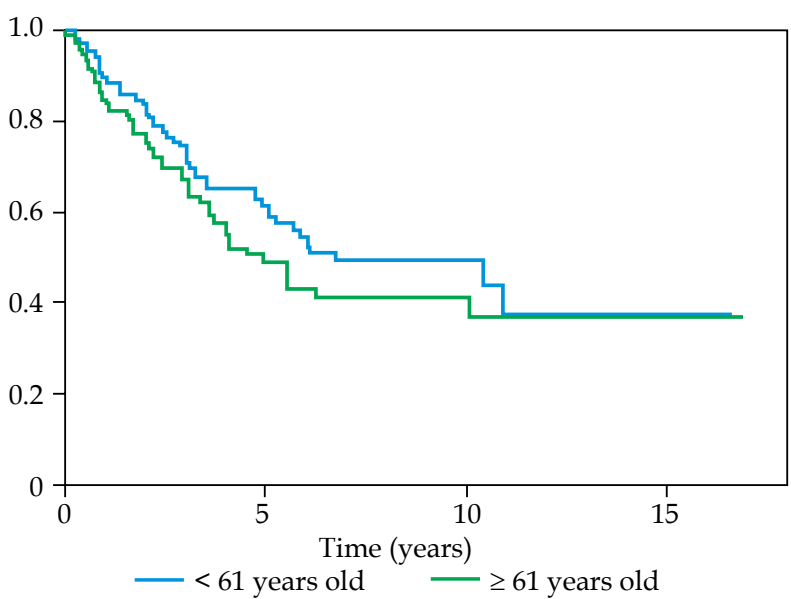

CSF: Tumor shape, $p=0.028$

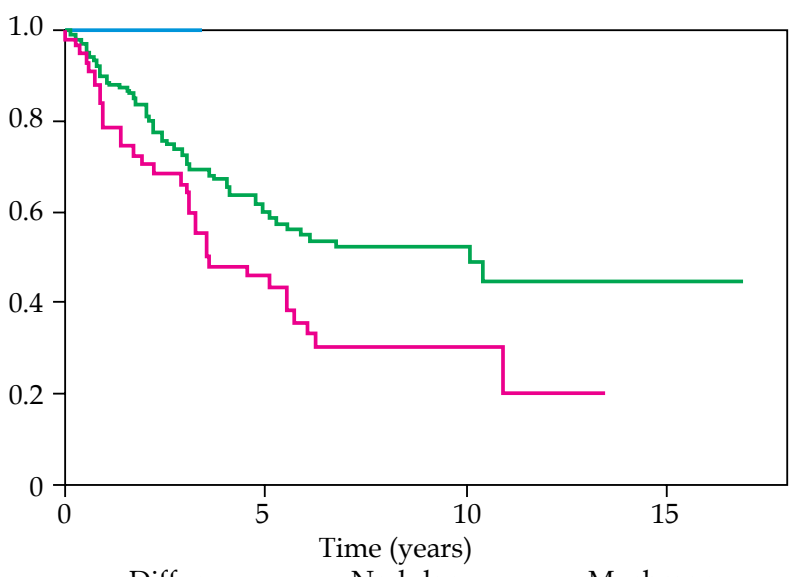

CSF: Dose to lens, $p<0.001$

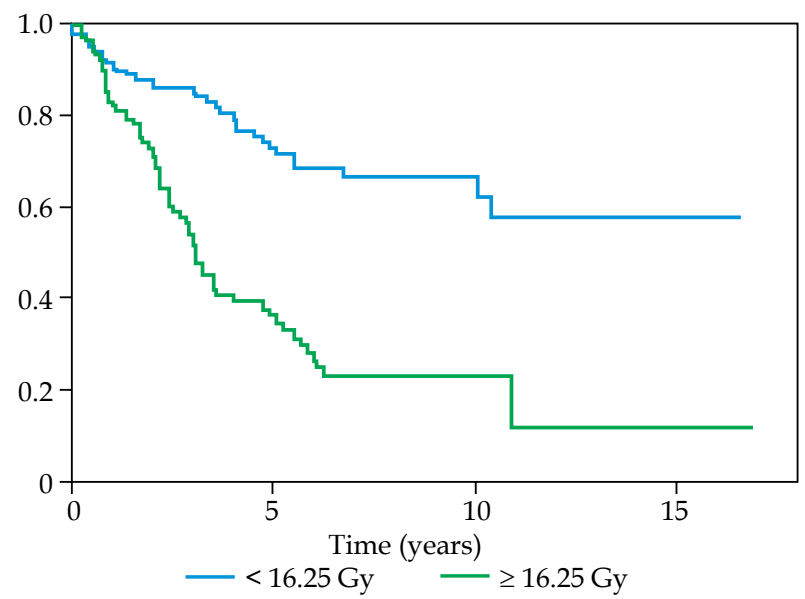

CSF: Type of plaque, $p=0.030$

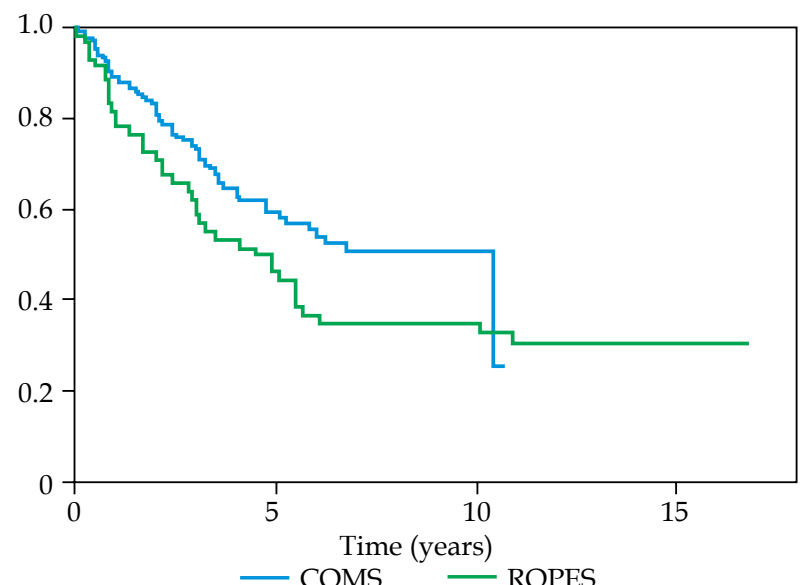

Fig. 3. Kaplan-Meier cumulative survival functions for the cataracts event. For quantitative variables, we shared the sample into its median value in order to ensure the same number of data in both branches. For the qualitative variables, split was already made. The curves in each of the graphs are not overlapping and there is statistically significant difference by Log-rank test $(p<0.05)$, except age

$79 \%$ (95\% CI: $73-85 \%), 66 \%$ (95\% CI: $57-75 \%)$, and $61 \%$ (95\% CI: $51-71 \%)$, respectively (Table 1 ). The mean time to local failure was 157 months (95\% CI: 142-171).

Multivariate logistic regression analysis including age revealed that age (HR: 0.975; 95\% CI: 0.956-0.995; $p=0.015$ ) notched vs. not notched shape plaque (HR: 2.025; 95\% CI: 1.002-4.094; $p=0.049)$, longest basal dimension (HR: 1.174; 95\% CI: 1.057-1.304; $p=0.003$ ), and BED to ON (HR: 1.002; 95\% CI: 1.000-1.003; $p=0.0016)$ were significant (Table 2).

Figure 5 shows the study of survival curves for the relevant variables of the multivariate study. All four variables (age, shape plaque, longest basal dimension, and BED to ON) analyzed by the Log-rank test reported $p$ values less than 0.05 , so the survival curves differ significantly.

\section{Vitreous hemorrhage}

From our cohort of 243 patients, vitreous hemorrhage was observed in $43(18 \%)$ patients. Actuarial KaplanMeier curves and confidence intervals are described in Figure 1. The 3-, 5-, 10-, and 15-year probability for retinopathy-free recurrence were: 87\% (95\% CI: 82-92\%), 83\%
(95\% CI: 77-89\%), 75\% (95\% CI: 68-82\%), and 73\% (95\% CI: $65-81 \%)$, respectively (Table 1). The mean time to local failure was 174 months (95\% CI: 162-187).

Multivariate logistic regression analysis including age revealed that age (HR: 1.030; 95\% CI: 1.004-1.057; $p=$ 0.026), tumor apical height (HR: 1.157; 95\% CI: 0.999-1.341; $p=0.049$ ), and mushroom tumor shape vs. nodular (HR: 0.442; 95\% CI: 0.208-0.855; $p=0.017$ ) were significant (Table 2).

Figure 6 shows the study of survival curves for the relevant variables of the multivariate study. Two variables (tumor apical height and tumor shape) analyzed by the Log-rank test reported $p$ values less than 0.05 , so the survival curves differ significantly. Log-rank test for age was not statistically significant.

\section{Neovascular glaucoma}

From our cohort of 243 patients, NVG was observed in $29(12 \%)$ patients. Actuarial Kaplan-Meier curves and confidence intervals are described in Figure 1. The 3-, 5-, $10-$, and 15-year probability for retinopathy-free recurrence were: $92 \%$ (95\% CI: 88-96\%), 89\% (95\% CI: 85-93\%), $81 \%$ (95\% CI: 73-89\%), and \% (95\% CI: $66-86 \%)$, respec- 
CSF: Tumor apical height, $p<0.001$

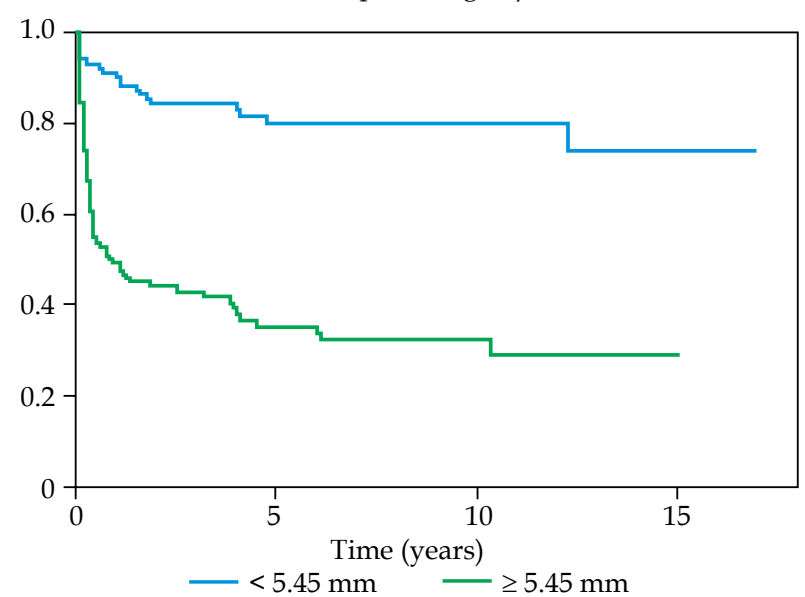

CSF: Size plaque, $p<0.001$

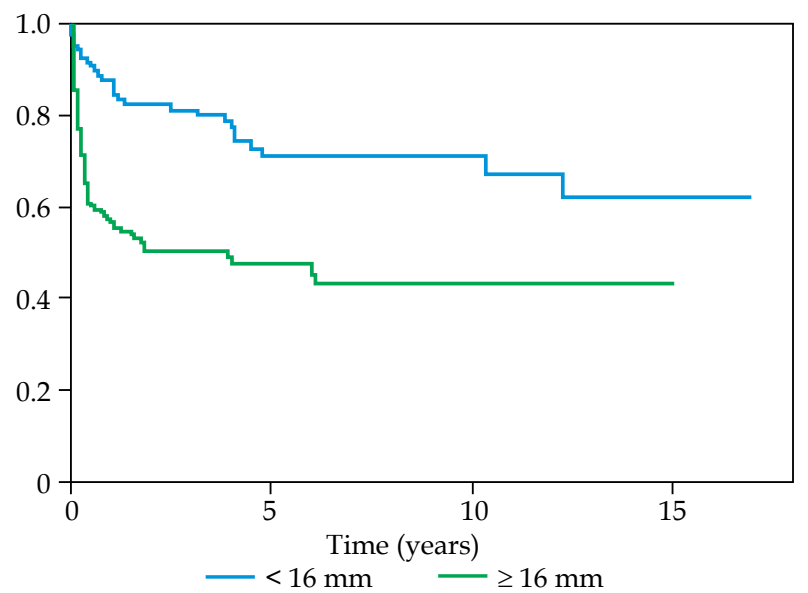

Fig. 4. Kaplan-Meier cumulative survival functions for the retinal detachment event. For quantitative variables, we shared the sample into its median value in order to ensure the same number of data in both branches. For the qualitative variables, split was already made. The curves in each of the graphs are not overlapping and there is statistically significant difference by Log-rank test $(p<0.05)$

tively (Figure 3). The mean time to local failure was 186 months (95\% CI: 173-198).

Multivariate logistic regression analysis including age revealed that tumor apical height (HR: 1.666; 95\% CI: 1.386-2.003; $p=0.002$ ) and BED to foveola (HR: 1.001; 95\% CI: 1.001-1.002; $p=0.003$ ) were significant (Table 2).

Figure 7 shows the study of survival curves for the relevant variables of the multivariate study. All two variables (tumor apical height and BED to foveola) analyzed by the Log-rank test reported $p$ values less than 0.05 , so the survival curves differ significantly.

\section{Discussion}

Posterior uveal melanomas are very resistant tumors, so doses to eradicate them are associated with a substantial risk of radiation damage to the structures attached, mainly the lens, retina, fovea, and optic nerve. In addition, the necrotic tumor tissue is a powerful irritant. These facts, together with the weakness of the structures of the eyeball, means that small necrotic areas may cause great inflammatory reactions [40].

The volume within the eyeball, on which the tumor grows, will inevitably be within $100 \%$ of the prescription dose; thus, the underlying area, retina and sclera, usually suffers a total atrophy due to radiation. These effects are particularly important in tumors that involve situations close to the macula and/or the optic nerve.

In this report, we present our experience after plaque brachytherapy and the possible relationship with clinical features including radiobiological doses, among others, in a large series of patients from a single center. A homogeneous group of patients affected by posterior uveal melanoma was selected.

This study is the first to correlate delivered radiobiological dose and side effects by means Dale's equations and Cox's proportional hazards models. Previous studies have been developed by these same authors for the loss of visual acuity [24], local control, eyeball conservation, and mortality [25]. A multi-center study involving larger patient population may confirm or disprove the findings.

The complications studied here for treatment with episcleral brachytherapy were the result of the late effects of ionizing radiation. Although some of them have appeared in low percentages, they are still important. While it is true that there are complications that are attributable to radiation, others will be closely linked to the geographical location of the tumor as well as its morphology.

\section{Radiation retinopathy}

The incidence of radiation retinopathy varies widely according to the authors, and it is a slowly evolving vasculopathy with a manifestation in varying degrees. The uncertainty regarding its definition can cause lack of precision when establishing the diagnosis and register it as such [26].

The regression of proportional risks finds the greatest age and the most anterior location of the tumor as protective factors. Specifically, the location of the anterior border in the ciliary body presents 3 times less risk than if it is located in the posterior segments of the eye. As unfavorable factors, we found the highest tumor height and the highest dose in the fovea. A more anterior location, away from the fovea, is compatible with a lower dose.

Multivariate studies carried out by some authors obtained as significant values in many different features, depending on the variables analyzed: dose to the macula higher than 90 Gy [31], a shorter distance to the fovea [31], distance of the tumor from the optic disc, male gender [31], higher radiation doses [31], tumor thicker than $4 \mathrm{~mm}[31,41]$, younger age [9,42], older age [43], diabetes [42,43], dose at $5 \mathrm{~mm}$ of the tumor [41], higher dose to sclera [41], dose to the apex [41], hypertension [42], anterior localization $[44,45]$, closer distance to the macula [46], and temporal localization [47] were statistically significant risks factors for developing radiation retinopathy. 
CSF: Age, $p<0.001$

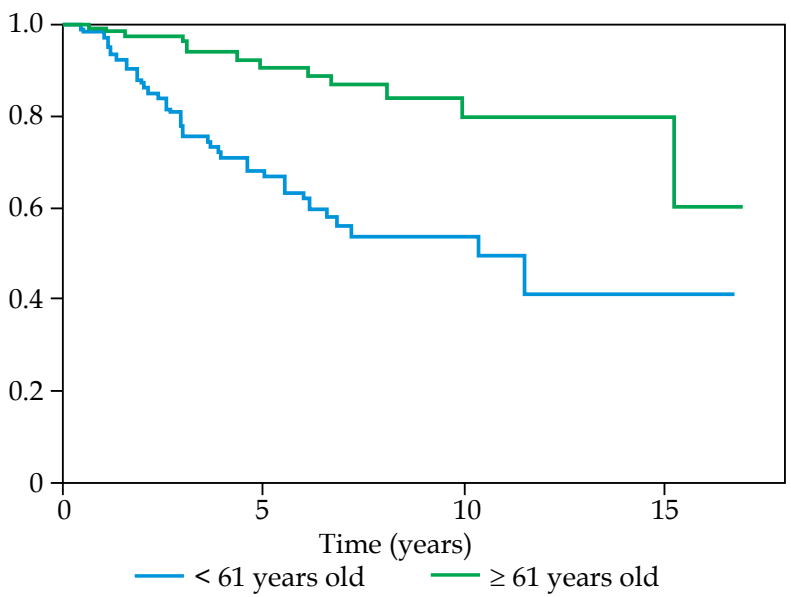

CSF: BED to ON, $p<0.001$

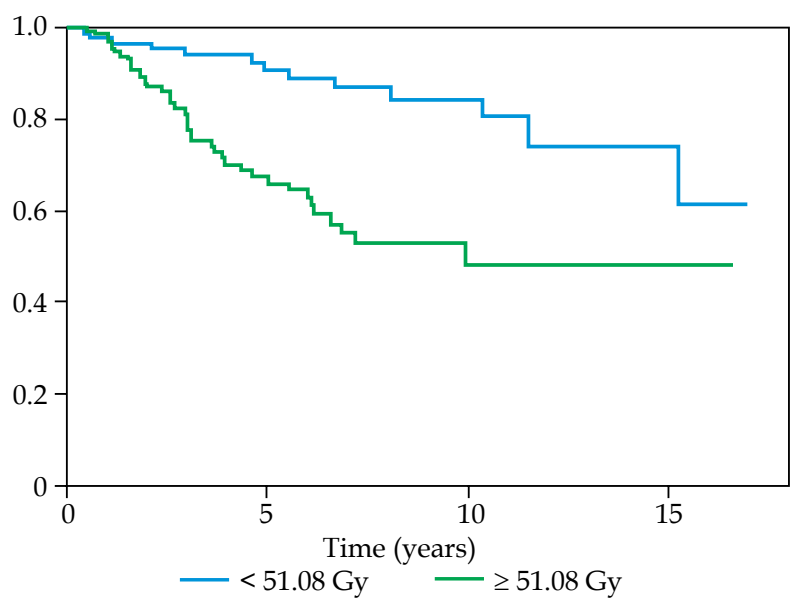

CSF: Longest basal dimension, $p=0.007$

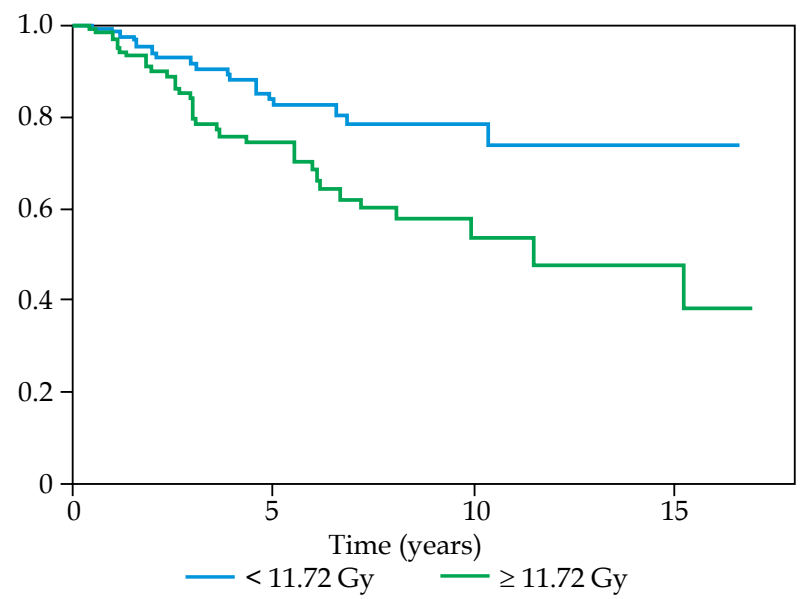

CSF: Shape of plaque, $p=0.037$

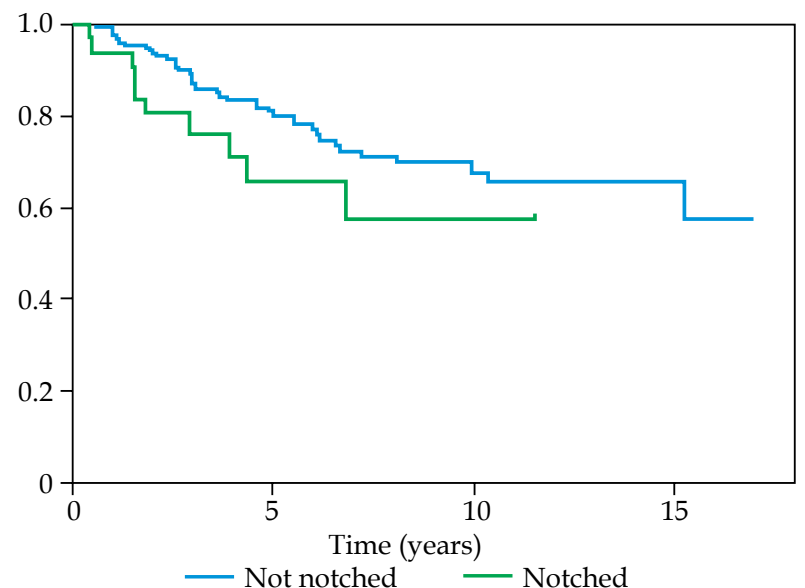

Fig. 5. Kaplan-Meier cumulative survival functions for the ON. For quantitative variables, we shared the sample into its median value in order to ensure the same number of data in both branches. For the qualitative variables, split was already made. The curves in each of the graphs are not overlapping and there is statistically significant difference by Log-rank test $(p<0.05)$

The dose in the fovea is the only factor that, as far as possible, we can control, so that its optimization can have favorable clinical repercussions for the patient. Even when the risk of optic neuropathy due to radiation can be reduced by personalized dosimetry and treatment planning, there are certain conditions such as the height of the tumor and the location of the anterior border that are not controllable.

\section{Cataracts}

Cataract disorder is a very common side effect after the treatment. The lens are the most radiosensitive structures and shows clinically visible damage with $0.5 \mathrm{~Gy}$ within 2 to 3 years [48]. The latent period between exposure and onset appears to be inversely related to dose [49]. Cataract surgery after radiotherapy is a completely safe procedure and not exposed to additional risks [50]. Approximately, one third of patients suffered from cataract at 3 years, progressively increasing to $60 \%$ at 15 years. Comparable, and even better, with values already reported by COMS [51] $(n=532), 68 \%$ at 5 years.

Age, tumor shape, type of plaque, and dose to lens were relevant in ours study. A higher physical dose to the lens as statistically significant factor is compatible with the process of cataract formation that is stochastic, and the most important fact to avoid it is to minimize the time of exposure to the implant as well as the total dose.

With regards to other studies with patients treated with episcleral brachytherapy, most agree to associate the highest dose in the lens with greater toxicity $[31,41,52,53,54]$, and also pole posterior affectation [54], male [55], higher age [55], longest basal dimension [55], posterior localization [44], and anterior localization [56].

\section{Retinal detachment}

Retinal detachment often resolves spontaneously in the first 6 months after radiotherapy. In some cases, it may be persistent, possibly due to the large inflammation in the area of the irradiated tumor and vascular damage because of the treatment.

This side effect can put at risk the visual function either by causing loss of visibility due to the lack of vasculature in the retina (with subsequent necrosis) or by contributing to the development of NVG. Some authors point out that persistent or recurrent retinal detachment after radiotherapy can be a sign of disease activity $[57,58]$ 
CSF: Age, $p=0.172$

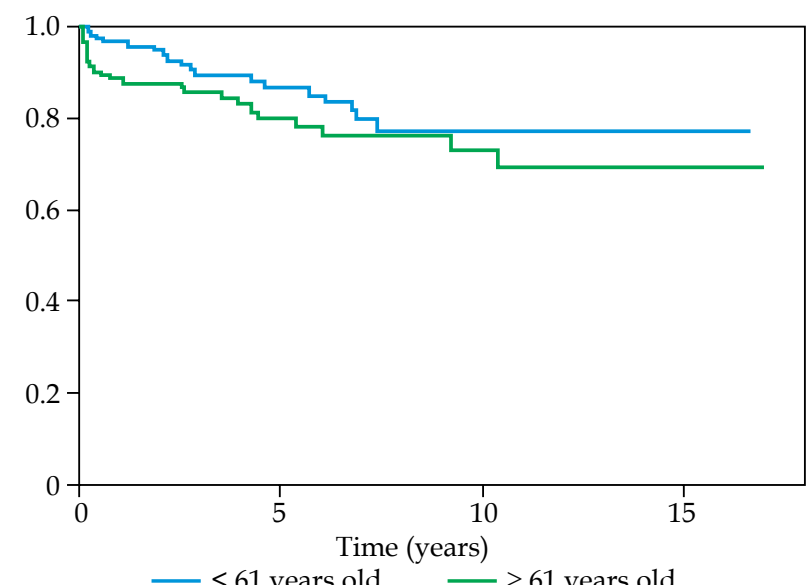

CSF: Tumor shape, $p<0.001$

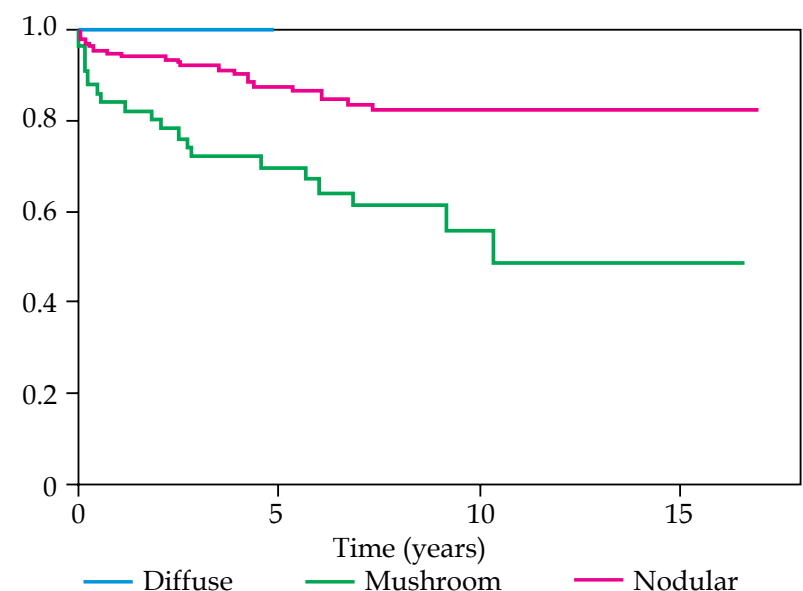

and even constitutes itself as a prognostic factor for failure of local control and enucleation $[51,57]$.

The survival of the event at 3 years was about two thirds, and half of the patients had suffered at 10 years stabilizing its figure from this point. Retinal detachment varies widely according to the authors from 3\% [9] $(n=156)$ to $71 \%$ [54] $(n=96)$ depending on the authors at 5 years. The high incidence during the first year, almost $30 \%$ of the patients, is due to the fact that many of them present retinal detachment before the treatment during the first revisions. It often resolves favorably through the first months. Due to characteristics of the statistical analysis, once the event has occurred, the patient leaves the study, so the number of real patients affected by a retinal detachment maintained over time may be overestimated. In addition, exudative retinal detachments resulting from radiation retinopathy have been included in our database. They are frequent in the evolution associated with tumor necrosis and it disappears later over the years.

Tumor apical height and size of the plaque, related with longest basal dimension, were the only statistically significant factors. In literature, there are very few references in relation to the proportional risk analysis that allow us to compare the prognostic variables found in our study with the results of other authors. Higher size of

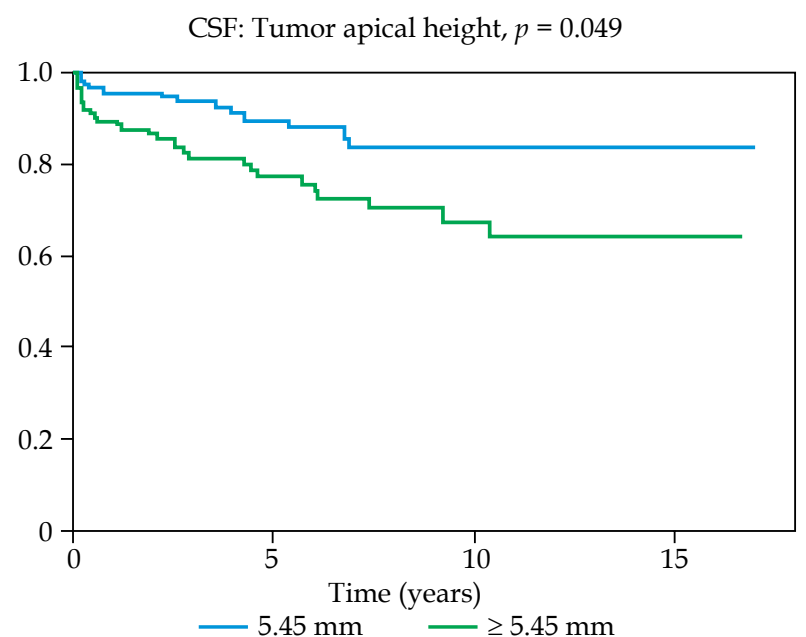

Fig. 6. Kaplan-Meier cumulative survival functions for the vitreous hemorrhage event. For quantitative variables, we shared the sample into its median value in order to ensure the same number of data in both branches. For the qualitative variables, split was already made. The curves in each of the graphs are not overlapping and there is statistically significant difference by Log-rank test $(p<0.05)$, except age

the tumor $[59,60]$, posterior localization $[59,60]$, and the presence of loops and microvascular networks [59,60], younger age [9], higher dose-rate to the optic disc [9], smaller diameter of the base [54], and ciliary body tumors [54].

\section{Radiation optic neuropathy}

Optic neuropathy often causes a severe and irreversible loss of vision for the patient who suffers from the disease and there is no effective treatment. $18 \%$ of patients present it after 3 years of treatment and the number increases to $50 \%$ at 15 years of follow-up. It is comparable to some series as Puusaari [54] $(n=96) 46 \%$ at 5 years.

Regarding the multivariable analysis of proportional risks, older age is a protective factor. The longest basal diameter and the higher biological dose were factors of worse prognosis. It is noteworthy that the juxtapapillary involvement, which includes the optic nerve, has not been statistically significant.

That is compatible with some authors suggesting that doses of optic nerve tolerance are between 30 and 60 Gy $[28,29,61,62,63]$ for iodine treatments to guarantee treatment with low complication of optic neuropathy. Multivariate studies carried out by some authors obtained significant values in many different features depending 
CSF: Tumor apical height, $p<0.001$

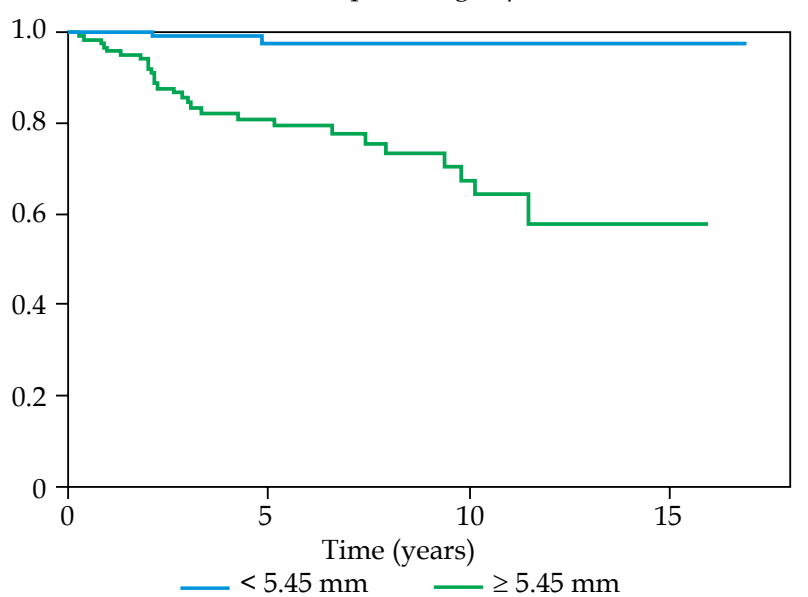

CSF: BED to foveola, $p=0.036$

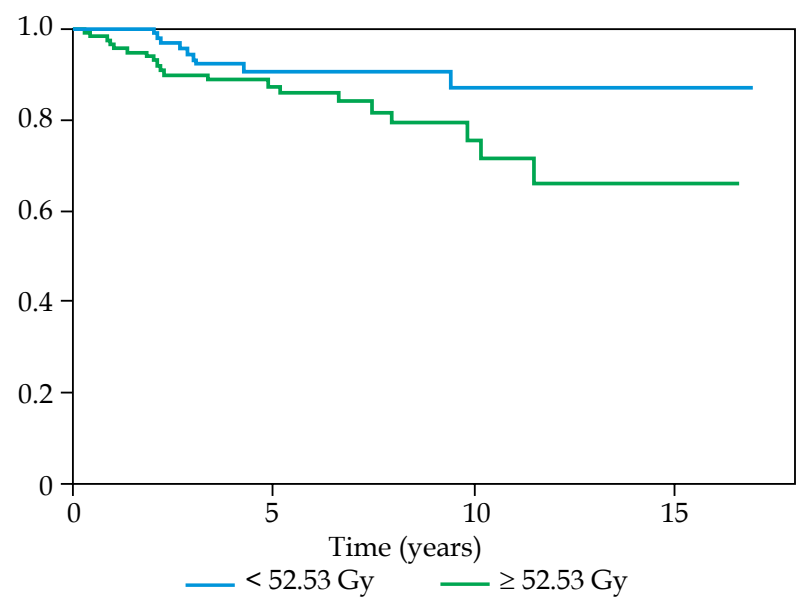

Fig. 7. Kaplan-Meier cumulative survival functions for the retinal neovascular glaucoma. For quantitative variables, we shared the sample into its median value in order to ensure the same number of data in both branches. For the qualitative variables, split was already made. The curves in each of the graphs are not overlapping and there is statistically significant difference by Log-rank test $(p<0.05)$

on the variables analyzed: higher dose to the macula [41], higher dose to optic nerve $[9,41,53]$, tumor proximity to the optic nerve [9,31,54], fewer basal diameter [9], secondary retinal detachment [9], and higher age [31].

\section{Vitreous hemorrhage}

Once the treatment with brachytherapy has been carried out, the vitreous hemorrhage can appear either as a consequence of the induced tumor necrosis or by the vascular alterations produced by the radiation. It is remarkable that bleeding makes it one causes of acutely or subacutely decreased vision. Fortunately, it can be approached very effectively by the ophthalmological team. At 3 years, $13 \%$ of the patients suffered it and the number is doubled when we analyze the results at 10 years, when it remains constant and there are no new registered events.

Our study has found as unfavorable variables for the vitreous hemorrhages: the older age, the greater height, and the shape of mushroom. It seems that the erosion in the Buch membrane (characteristically produced by a mushroom-shaped tumor) is binding.

In the literature, there are only two studies that attempt to relate the dose variables with the appearance of vitreous hemorrhage. Some studies have not found correlations with the dose to risk organs [54]; nevertheless, other authors claim that vitreous hemorrhages occurred in those eyes that had received high doses of sclera and crystalline [53].

\section{Neovascular glaucoma}

NVG can also develop in healthy eyes and not treated spontaneously. Its incidence after brachytherapy treatment is especially remarkable. Ischemia associated with radiation-induced retinopathy may cause proliferation of new vessels in the iris and, as a last consequence, NVG. Although, the mechanisms are not fully understood [64], NGV often causes a profound and irreversible loss of vision. In addition, it can cause a great sensation of pain in the eye and finally end up with a secondary enucleation.
Twelve percent of patients present NVG in the first 5 years after treatment. The number of NGV described by the authors varies widely. Shields [65] $(n=354)$ found $21 \%$ after treatment for the same period of time.

The highest tumor apical height and the highest biological dose in the foveola were the two variables statistically significant in multivariate studies. The first variable increases the risk by $70 \%$ per millimeter. Multivariate studies carried out by some authors obtained significant values in many different features depending on the variables analyzed: higher the dose in the opposite retina [54], high preoperative intraocular pressure [54], a previous retinal detachment [54], larger tumor size [65,66], high-dose to sclera [53], high-dose to lens [41,53], highdose to fovea [53], and male gender [30].

\section{Study limitations}

Our retrospective study reports results of the treatment of patients with choroidal melanoma in Spain from 1996 to 2016. This study has several limitations. Only clinical factors have been considered but posterior uveal melanoma prognosis has been shown to be dependent as well as histopathologic and cytogenetic factors and chromosomal mutations [67].

The main limitations of the radiobiological modeling are the lack of control of all the biological mechanisms involved in the expression of a certain radiation effect, and the uncertainties in the formulation of the models from clinical data [68]. Therefore, these models may not reflect normal tissue complications properly and as result, the analysis could fail. Secondly, Kaplan-Meier curves behave poorly in the tails and the reliability of the estimates is intuitively bad, when there are less than $10 \%$ patients remaining in the cohort [39].

Cox models using maximum probability can perform poorly when there are few events. Specific problems include predictions that are too extreme and poor discrimination between low-risk and high-risk patients. The model can be unreliable if the datasets contain few 
events, which may be the case if either the disease or the event of interest is rare [69].

Despite these weaknesses, this review still provides valuable information regarding treatment factors that predict side effects after epiescleral brachytherapy.

\section{Conclusions}

Complications and radiation-related side effects are common among patients treated with iodine brachytherapy for posterior uveal melanoma. The risk for those largely depends on individual tumor parameters in most cases.

Development of complications was related to the tumor location and dose to non-tumor structures. Toxicity in our series was moderate; brachytherapy is a good conservative treatment for medium-sized posterior uveal melanoma and is a reasonable alternative to enucleation.

Our findings support earlier reports that tumor factors in addition to radiation treatment may contribute to abnormalities.

Complications demands an adequate understanding of the biological effects of the brachytherapy on the target tumor as well as on healthy ocular tissues.

\section{Acknowledgements}

This study was partially supported by Varian Medical Systems Ibérica, S.L.

The authors would like to thank the referees for the valuable comments on our manuscript. D. Miguel's contributions as a part of his $\mathrm{PhD}$ thesis under the supervision of F. López-Lara and J. de Frutos-Baraja at the University of Valladolid.

\section{Disclosure}

The authors report no conflict of interest.

\section{References}

1. Virgili G, Gatta G, Ciccolallo L et al. Incidence of uveal melanoma in Europe. Ophthalmology 2007; 114: 2309-2315.

2. Singh AD, Turell ME, Topham AK. Uveal melanoma: trends in incidence, treatment, and survival. Ophthalmology 2011; 118: 1881-1885.

3. Shields JA, Shields CL, Donoso LA. Management of posterior uveal melanoma. Surv Ophthalmol 1991; 36: 161-195.

4. Rao YJ, Sein J, Badiyan S et al. Patterns of care and survival outcomes after treatment for uveal melanoma in the postcoms era (2004-2013): a surveillance, epidemiology, and end results analysis. J Contemp Brachytherapy 2017; 9: 453-465.

5. Shields JA, Shields CL. Management of posterior uveal melanoma: past, present, and future: the 2014 Charles L. Schepens lecture. Ophthalmology 2015; 122: 414-428.

6. Damato B. Progress in the management of patients with uveal melanoma. The 2012 Ashton Lecture. Eye (Lond) 2012; 26: 1157-1172.

7. American Brachytherapy Society - Ophthalmic Oncology Task Force; Simpson ER, Gallie B, Laperrierre N et al. The American Brachytherapy Society consensus guidelines for plaque brachytherapy of uveal melanoma and retinoblastoma. Brachytherapy 2014; 13: 1-14.

8. Chiu-Tsao ST, Astrahan MA, Finger PT et al. Dosimetry of (125)I and (103)Pd COMS eye plaques for intraocular tumors: report of Task Group 129 by the AAPM and ABS. Med Phys 2012; 39: 6161-6184.

9. Jensen AW, Petersen IA, Kline RW et al. Radiation complications and tumor control after 125I plaque brachytherapy for ocular melanoma. Int J Radiat Oncol Biol Phys 2005; 63: 101-108.

10. Brady LW, Shields J, Augusburger J et al. Complications from radiation therapy to the eye. Front Radiat Ther Oncol 1989; 23: 238-254

11. Summanen $\mathrm{P}$, Immonen I, Kivela $\mathrm{T}$ et al. Radiation related complications after ruthenium plaque radiotherapy of uveal melanoma. Br J Ophthalmol 1996; 80: 732-739.

12. Langmann A, Langmann G, Unlücerci C et al. Motility disorders in brachytherapy of choroid melanomas with Ru106 applicators. Ophthalmologe 1995; 92: 76-78 [Article in German].

13. Sener EC, Kiratli H, Gedik S et al. Ocular motility disturbances after episcleral plaque brachytherapy for uveal melanoma. J AAPOS 2004; 8: 38-45.

14. Tagliaferri L, Pagliara MM, Masciocchi C et al. Nomogram for predicting radiation maculopathy in patients treated with Ruthenium-106 plaque brachytherapy for uveal melanoma. J Contemp Brachytherapy 2017; 9: 540-547.

15. Rospond-Kubiak I, Wróblewska-Zierhoffer M, TwardoszPawlik H. Ruthenium brachytherapy for uveal melanoma single institution experience. J Contemp Brachytherapy 2017; 9: 548-552.

16. Parsons JT, Bova FJ, Mendenhall WM et al. Response of the normal eye to high dose radiotherapy. Oncology (Willston Park) 1996; 10: 837-847.

17. Muller HJ. Artificial transmutation of the gene. Science 1927; 66: 84-87.

18. Fowler JF. The linear-quadratic formula and progress in fractionated radiotherapy. Br J Radiol 1989; 62: 679-694.

19. Dale RG. The application of the linear-quadratic dose-effect equation to fractionated and protracted radiotherapy. $\mathrm{Br} \mathrm{J}$ Radiol 1985; 58: 515-528.

20. Dale RG. Some theoretical derivations relating to the tissue dosimetry of brachytherapy nuclides, with particular reference to iodine-125. Med Phys 1983; 10: 176-183.

21. Gagne NL, Leonard KL, Huber KE et al. BEDVH-A method for evaluating biologically effective dose volume histograms: application to eye plaque brachytherapy implants. Med Phys 2012; 39: 976-983.

22. Gagne NL, Leonard KL, Rivard MJ. Radiobiology for eye plaque brachytherapy and evaluation of implant duration and radionuclide choice using an objective function. Med Phys 2012; 39: 3332-3342.

23. Gagne NL, Cutright DR, Rivard MJ. Keeping an eye on the ring: COMS plaque loading optimization for improved dose conformity and homogeneity. J Contemp Brachytherapy 2012; 4: 165-175.

24. Miguel D, de Frutos-Baraja JM, López-Lara F et al. Visual outcome after posterior uveal melanoma episcleral brachytherapy including radiobiological doses. J Contemp Brachytherapy 2018; 10: 123-131.

25. Miguel D, de Frutos-Baraja JM, López-Lara F et al. Radiobiological doses, tumor, and treatment features influence on local control, enucleation rates, and survival after epiescleral brachytherapy. A 20-year retrospective analysis from a singleinstitution: part I. J Contemp Brachytherapy 2018; 10: 337-346.

26. Brown GC, Shields JA, Sanborn G, et al. Radiation retinopathy. Ophthalmology 1982; 89: 1494-1501.

27. Archer DB, Amoaku WM, Gardiner TA. Radiation retinopathy - clinical, histopathological, ultrastructural and experimental correlations. Eye (Lond) 1991; 5 (Pt 2): 239-251.

28. Brown GC, Shields JA, Sanborn G et al. Radiation optic neuropathy. Ophthalmology 1982; 89: 1489-1493. 
29. Gragoudas ES, Li W, Lane AM et al. Risk factors for radiation maculopathy and papillopathy after intraocular irradiation. Ophthalmology 1999; 106: 1571-1578.

30. Merriam GR, Focht EF. A clinical study of radiation cataracts and the relationship to dose. Am J Roentgenol Radium Ther Nucl Med 1957; 77: 759-785.

31. Stack R, Elder M, Abdelaal A, et al. New Zealand experience of I125 brachytherapy for choroidal melanoma. Clin Exp Ophthalmol 2005; 33: 490-494.

32. Petrovich Z, McDonnell JM, Palmer D et al. Histopathologic changes following irradiation for uveal tract melanoma. Am J Clin Oncol 1994; 17: 298-306.

33. Burris CKH, Rodriguez ME, Potter HD. Scleral Necrosis Simulating Recurrent Uveal Melanoma after Plaque Brachytherapy. Ophthalmology 2016; 123: 1761

34. Bland JM, Altman DG. Survival probabilities (the KaplanMeier method). BMJ 1998; 317: 1572-1580.

35. Lunn M, McNeil D. Applying Cox regression to competing risks. Biometrics 1995; 51: 524-532.

36. Bursac Z, Gauss CH, Williams DK et al. Purposeful selection of variables in logistic regression. Source Code Biol Med 2008; 3: 17.

37. Benichou C, Danan G, Flahault A. Causality assessment of adverse reactions to drugs - II. An original model for validation of drug causality assessment methods: case reports with positive rechallenge. J Clin Epidemiol 1993; 46: 1331-1336.

38. Danan G, Benichou C. Causality assessment of adverse reactions to drugs - I. A novel method based on the conclusions of international consensus meetings: application to drug-induced liver injuries. J Clin Epidemiol 1993; 46: 1323-1330.

39. Rich JT, Neely JG, Paniello RC et al. A practical guide to understanding Kaplan-Meier curves. Otolaryngol Head Neck Surg 2010; 143: 331-336.

40. Groenewald C, Konstantinidis L, Damato B. Effects of radiotherapy on uveal melanomas and adjacent tissues. Eye (Lond) 2013; 27: 163-171.

41. Wagner A, Chen A, Cook $\mathrm{T}$ et al. Outcomes and Control Rates for I-125 Plaque Brachytherapy for Uveal Melanoma: ACommunity-Based Institutional Experience.ISRNOphthalmo 2014; 2014: 1-7.

42. Krema H, Xu W, Payne D et al. Factors predictive of radiation retinopathy post 125 Iodine brachytherapy for uveal melanoma. Can J Ophthalmol 2011; 46: 158-163.

43. De Potter P, Shields CL, Shields JA et al. Plaque radiotherapy for juxtapapillary choroidal melanoma. Visual acuity and survival outcome. Arch Ophthalmol 1996; 114: 1357-1365.

44. Finger PT. Tumour location affects the incidence of cataract and retinopathy after ophthalmic plaque radiation therapy. Br J Ophthalmol 2000; 84: 1068-1070.

45. Gündüz K, Shields CL, Shields JA et al. Radiation retinopathy following plaque radiotherapy for posterior uveal melanoma. Arch Ophthalmol 1999; 117: 609-614.

46. McLean IW, Foster WD, Zimmerman LE. Uveal melanoma location, size, cell type, and enucleation as risk factors in metastasis. Hum Pathol 1982; 13: 123-132.

47. Wen JC, Oliver SC, McCannel TA. Ocular complications following I-125 brachytherapy for choroidal melanoma. Eye (Lond) 2009; 23: 1254-1268.

48. Stewart FA, Akleyev AV, Hauer-Jensen M et al. ICRP publication 118: ICRP Statement on Tissue Reactions and Early and Late Effects of Radiation in Normal Tissues and Organs - Threshold Doses for Tissue Reactions in a Radiation Protection Context. Clement CH, ed. Ann ICRP 2012; 41: 1-322.

49. Cucinotta FA, Manuel FK, Jones J et al. Space radiation and cataracts in astronauts. Radiat Res 2001; 156 (5 Pt 1): 460-466.

50. Quivey JM, Char DH, Phillips TL et al. High intensity 125-iodine (125I) plaque treatment of uveal melanoma. Int J Radiat Oncol Biol Phys 1993; 26: 613-618.
51. Jampol LM, Moy CS, Murray TG et al. The COMS randomized trial of iodine 125 brachytherapy for choroidal melanoma: IV. Local treatment failure and enucleation in the first 5 years after brachytherapy. COMS report no. 19. Ophthalmology 2002; 109: 2197-2206.

52. Collaborative Ocular Melanoma Study Group. Incidence of cataract and outcomes after cataract surgery in the first 5 years after iodine 125 brachytherapy in the Collaborative Ocular Melanoma Study: COMS Report No. 27. Ophthalmology 2007; 114: 1363-1371.

53. Krohn J, Monge OR, Skorpen TN et al. Posterior uveal melanoma treated with I-125 brachytherapy or primary enucleation. Eye 2008; 22: 1398-1403.

54. Puusaari I, Heikkonen J, Kivelä T. Ocular complications after iodine brachytherapy for large uveal melanomas. Ophthalmology 2004; 111: 1768-1777.

55. Lumbroso-Le Rouic L, Charif Chefchaouni M, Levy C et al. 125I plaque brachytherapy for anterior uveal melanomas. Eye 2004; 18: 911-916.

56. Fontanesi J, Meyer D, Xu S et al. Treatment of choroidal melanoma with I-125 plaque. Int J Radiat Oncol Biol Phys 1993; 26: 619-623.

57. Shields CL, Shields JA, Kiratli H et al. Risk factors for growth and metastasis of small choroidal melanocytic lesions. Ophthalmology 1995; 102: 259-279.

58. Gass JD. Observation of suspected choroidal and ciliary body melanomas for evidence of growth prior to enucleation. Ophthalmology 1980; 87: 523-528.

59. Jensen OA. Malignant melanomas of the human uvea: 25-year follow-up of cases in Denmark, 1943-1952. Acta Ophthalmol 1982; 60: 161-182

60. Kivelä T, Eskelin S, Mäkitie T, et al. Exudative retinal detachment from malignant uveal melanoma: predictors and prognostic significance. Invest Ophthalmol Vis Sci 2001; 42: 2085-2093.

61. Puusaari I, Heikkonen J, Kivelä T. Effect of radiation dose on ocular complications after iodine brachytherapy for large uveal melanoma: Empirical data and simulation of collimating plaques. Investig Ophthalmol Vis Sci 2004; 45: 3425-3434.

62. Jiang GL, Tucker SL, Guttenberger R et al. Radiation-induced injury to the visual pathway. Radiother Oncol 1994; 30: 17-25.

63. Lommatzsch PK, Alberti W, Lommatzsch R et al. Radiation effects on the optic nerve observed after brachytherapy of choroidal melanomas with 106Ru/106Rh plaques. Graefe's Arch Clin Exp Ophthalmol 1994; 232: 482-487.

64. Puusaari I, Heikkonen J, Summanen P et al. Iodine Brachytherapy as an Alternative to Enucleation for Large Uveal Melanomas. Ophthalmology 2003; 110: 2223-2234.

65. Shields CL, Naseripour M, Cater J et al. Plaque Radiotherapy for Large Posterior Uveal Melanomas (> 8-mm thick) in 354 Consecutive Patients. Ophthalmology 2002; 109: 1838-1849.

66. Caminal JM, Padrón-Pérez N, Arias L et al. Transscleral resection without hypotensive anaesthesia vs iodine-125 plaque brachytherapy in the treatment of choroidal melanoma. Eye (Lond) 2016; 30: 833-842.

67. Kaliki S, Shields CL, Shields JA. Uveal melanoma: estimating prognosis. Indian J Ophthalmol 2015; 63: 93-102.

68. Fowler JF. 21 years of biologically effective dose. $\mathrm{Br}$ J Radiol 2010: 554-568.

69. Ambler G, Seaman S, Omar RZ. An evaluation of penalised survival methods for developing prognostic models with rare events. Stat Med 2012; 31: 1150-1161. 